* Discente em Faculdades Londrina.

** Doutor e Mestre em Ciência Jurídica pela Universidade Estadual do Norte do Paraná (UENP). Especialista em Direito Civil e Processo Civil. Graduado em Direito pela Universidade Estadual de Londrina (UEL). Professor e coordenador do Núcleo de Práticas Jurídicas em Faculdades Londrina.

\section{A Importância Dos Precedentes Judiciais Na Evolução Do Direito Brasileiro}

\author{
Gustavo Luppi Pezarini* \\ Rafael Gomieiro Pitta**
}

\begin{abstract}
Quem quer garantir a própria liberdade, deve preservar da opressão até o inimigo; pois, se fugir a esse dever, estará a estabelecer um precedente que até a ele próprio há de atingir. Thomas Paine
\end{abstract}

Como citar: PEZARINI, Gustavo Luppi; PITTA, Rafael Gomieiro. A importância dos precedentes judiciais na evolução do Direito brasileiro. Revista do Instituto de Direito Constitucional e Cidadania - IDCC, Londrina, v. 5, n. 1, p 31-44, jan/jul, 2020. ISSN: 2596-0075. https://doi.org/10.48159/revistadoidcc.v5n1.pezarini.pitta

Resumo:Ao criar um sistema de normatização de precedentes, o Código de Processo Civil de 2015 buscou padronizar a utilização do sistema de precedentes vinculantes e trouxe a possibilidade de aplicação da motivação dos precedentes não vinculantes mediante a aplicação da ratio decidendi pelos juízes em quaisquer instâncias, em franca busca pela coerência das decisões judiciais. Com base na obrigatoriedade da fundamentação das decisões judiciais, permite aos litigantes demonstrar como precedentes - vinculantes ou não - apontam o sentido da jurisprudência, vinculando ao menos a motivação do juiz. Este trabalho apresenta os conceitos necessários para que se possa fazer a análise do sistema de precedentes adotado no Brasil, bem como suas limitações, alcance e efetividade. Por fim, procura investigar como a cultura de precedentes pode ou não ser adaptada ao sistema Civil Law, contribuindo para a segurança jurídica das decisões judiciais, tornandoas mais efetivas e a prestação jurisdicional mais coesa e eficaz.

Palavras-Chave: Precedentes judiciais. Evolução do Direito brasileiro. Processo Civil.

Abstract:By creating a system of standardization of the precedents, the new Code of Civil Procedure sought to standardize the use of the system of binding precedents and brought the possibility of applying the motivation of non-binding precedents by applying ratio decidendi by the judges in any level, in a frank search for the coherence of judicial decisions. Based on the obligation to state reasons for judicial decisions, the system allows the litigants to demonstrate as precedents 
- binding or not - the meaning of jurisprudence, linking at least the motivation of the judge. This paper presents the concepts necessary for the analysis of the precedence system adopted in Brazil, as well as its limitations, scope and effectiveness. Finally, it seeks to investigate how the culture of precedents may or may not be adapted to the Civil Law system, contributing to the legal certainty of judicial decisions, making them more effective and the judicial performance more cohesive and effective.

KEYWORDS: Judicial precedents. Evolution of Brazilian Law. Civil Procedure. 


\section{INTRODUÇÃO}

O objetivo principal deste trabalho é demonstrar a importância dos precedentes para a evolução do Direito brasileiro. Na consecução desse objetivo, três objetivos secundários foram estabelecidos, quais sejam: a) Delimitar, sob a ótica do ordenamento jurídico brasileiro, o que são precedentes judiciais. b) Apresentar os contextos de vinculação das decisões judiciais ao sistema de precedentes seja por motivação, persuasão ou vinculação obrigatória, e por fim, c) demonstrar se a aplicação de precedentes poderia ser adaptada à realidade do Civil Law sem desvirtuar suas características essenciais, que serão apresentadas e diferenciadas do Common Law.

O referencial teórico utilizado aborda as questões e teorias iniciais relacionadas ao tema em estudo, sob a ótica de vários autores, por meio de revisão bibliográfica sistematizada. Foi utilizado o método teórico, mais necessariamente na pesquisa bibliográfica de obras, leis, e documentos eletrônicos que tratam do tema, sob prismas diversos, fazendo nascer a dialética acerca do assunto e sem pretender exaurir o debate, por fim, apresentam-se as considerações finais e as referências.

\section{DESENVOLVIMENTO}

\section{CIVIL LAW E COMMON LAW}

A principal distinção entre os sistemas de direito Civil Law e o Common Law se encontra nas fontes originárias do direito. Enquanto o primeiro, adotado pelos países da Europa continental e da América Latina, utiliza como principal fonte as leis, devidamente codificadas pelos legisladores, o segundo, adotado em países de tradição anglo-americana, com origem na Inglaterra, tem na decisão judicial, ou no precedente judicial, preenchidos determinados requisitos, a fonte principal do direito.

Etimologicamente, a palavra fonte tem raízes no termo latino fontis que possui significado semelhante a princípio, origem, causa ${ }^{1}$. A expressão fontes do direito diz respeito à origem do processo de elaboração de normas jurídicas que deverá reger as relações entre os indivíduos inseridos em uma mesma sociedade ou entre o Estado e seus cidadãos. Neste sentido, Miguel Reale demonstra que as fontes primárias do Direito devem ser dotadas de legitimidade dentro de seu sistema:

Muitas são, pois, as questões com que se defronta a Epistemologia Jurídica, que poderia ser definida como sendo a doutrina dos valores lógicos da realidade social do Direito, ou, por outras palavras, dos pressupostos lógicos que condicionam e legitimam o conhecimento jurídico, desde a Teoria Geral do Direito - que é a sua projeção imediata no plano empírico-positivo - até às distintas disciplinas em que se desdobra a Jurisprudência. ${ }^{2}$

A lógica jurídica, conceito diretamente relacionado ao modo de fluir de um processo ou do paradigma que relaciona os distintos processos que tenham em si semelhanças facto-jurídicas,

1 Dício: Dicionário online de Português. Disponível em $<$ https://www.dicio.com.br/fonte/ $>$ Acesso em 28/05/2020.

2 REALE, Miguel. Filosofia do direito. 19ª edição, 3ª tiragem. São Paulo: Saraiva, 2002, p. 306. 
também é um condutor rumo à coerência. A Ciência Dogmática do Direito, que abarca as nascentes de sistematização e até mesma da integração processual dos institutos jurídicos que a formam. Essa linha de estudo é determinante para a análise de como, com o advento do Código de Processo Civil de 2015 (Lei 13.105 de 16 de março de 2015) - CPC, os precedentes judiciais, que são fonte no direito anglo-americano, vêm disciplinar a conduta, ou pelo menos a forma de racionalizar o processo, pelos juízes brasileiros.

Cabe aqui delimitar a natureza da Hermenêutica Jurídica utilizada para a concepção dos "bens culturais de suporte ideal” insuscetíveis, que são a razão comum de ser para os sistemas jurídicos, tanto os baseados na lei quanto os que têm sua origem nos precedentes. Emerge assim, com o CPC de 2015, o manejo dos chamados "modelos jurídicos". ${ }^{3}$

\section{PRECEDENTE JUDICIAL}

\subsection{Definição}

O significado etimológico de precedente, como adjetivo, é algo que acontece de modo prévio, anterior, uma situação precedente a outra. Como substantivo masculino, é uma maneira comportamental utilizada como modelo ou referência para outra situação parecida ${ }^{4}$.

Esta análise infere ao termo precedente judicial, além da simples anterioridade de uma decisão judicial a outra, uma condição de modelo da primeira para a segunda, como explica Marinoni:

Seria possível pensar que toda decisão judicial é um precedente. Contudo, ambos não confundem, só havendo sentido falar de precedente quando se tem uma decisão dotada de determinadas características, basicamente a potencialidade de se firmar como paradigma para a orientação dos jurisdicionados e dos magistrados. ${ }^{5}$

A ideia de vinculação a precedentes surge em decorrência do sincretismo jurídico normativo, com a constitucionalização das leis infraconstitucionais, dentre eles o Código de Processo Civil, reeditado em 2015 sob a égide da Constituição Federal de 1988. Como forma de proporcionar a eficiência, princípio estampado no artigo $8^{\circ}$ do CPC, assim ensina Câmara acerca do sistema de precedentes:

A observância de um sistema de vinculação a precedentes, especialmente no que concerne ás causas repetitivas; a construção de mecanismos de antecipação de tutela, tanto para situações de urgência como para casos em que a antecipação se funda na evidência; a melhoria do sistema recursal, com diminuição de oportunidades recursais; tudo isso contribui para a duração mais razoável do processo. É, porém, sempre importante ter claro que só se pode cogitar de

3 REALE, Miguel. Filosofia do direito. $19^{a}$ edição, $3^{a}$ tiragem. São Paulo: Saraiva, 2002. p.306 e 307.

4 Dicionário on-line de português. Disponível em: $<\mathrm{https}$ ://www.dicio.com.br/precedente/> Acesso em $19 / 05 / 2020$.

5 MARINONI, Luiz Guilherme. Precedentes obrigatórios. São Paulo: Editora Revista dos Tribunais, 2010, p. 215. 
duração razoável do processo quando este é capaz de produzir os resultados a que se dirige. ${ }^{6}$

O dever de observância ao sistema de precedentes é um dos pontos mais controversos do CPC de 2015, haja vista que, em relação ao tema, não delimita de forma clara e objetiva sua extensão, proporcionando interpretações sobre quais precedentes devem, efetivamente, ser observados.

É ainda objeto de árduas críticas pelos estudiosos do direito comparado, principalmente entre os sistemas de Civil Law romano-germânico adotado no Brasil e o Common Law anglosaxônico adotado em países como Inglaterra e Estados Unidos, que apontam a desvinculação obrigatória dos juízes aos precedentes como causa de inefetividade do sistema de precedentes brasileiro.

\subsection{MOTIVAÇÃO, PERSUASÃO OU VINCULAÇÃO OBRIGATÓRIA}

O CPC alterou a eficácia do sistema de precedentes quando elencou, no artigo 489, dentre os elementos obrigatórios das decisões judiciais, a necessidade de demonstrar a distinção entre o caso concreto e o precedente invocado pela parte.

Nesse ponto se ressalta a importância dada pelo Código ao precedente, pois em que pese o mencionado artigo 489 versar sobre a sentença, seu parágrafo primeiro faz alusão a qualquer decisão judicial, seja interlocutória, sentença ou acórdão. Nas palavras de Conceição:

Nula também será a decisão em que o juiz deixe de esclarecer racionalmente as escolhas que fez; que aplique o precedente ou a súmula sem demonstrar a sua similitude fática com o caso em exame, ou, ao contrário, que deixe de aplicar o precedente ou a súmula, sem expor o aspecto que distinguiria os casos e imporia solução diferente. O art. 489, incisos V e VI, do CPC/2015, dentre outros ao longo do Código, deixa claro que o legislador deu ênfase ao respeito aos precedentes, sendo essa uma das linhas mestras do novo Código Civil. ${ }^{7}$

O artigo 927 do CPC trouxe o rol de precedentes que são dotados de eficácia normativa, ou seja, de observação obrigatória sob pena de reclamação, instrumento previsto no CPC (artigo 988) cujo objetivo é garantir sua eficácia.

Com o mesmo fim, é inserido nos quesitos de admissibilidade o não conflito do pedido com os precedentes, sob pena do indeferimento liminar do pedido, como expõe Bueno:

É coerente o CPC de 2015 com o que ele próprio propõe quanto à eficácia dos precedentes dos Tribunais ao impor a improcedência liminar quando a petição

6 CÂMARA, Alexandre Freitas. O novo processo civil brasileiro. São Paulo: Atlas, 2015, p. 6.

7 CONCEIÇÃ̂, Maria Lucia Lins. Código de processo Civil Anotado. AASP, OAB Paraná, ISBN 97885-86893-00-1, 2017. p. 813. Disponível em: https://www.aasp.org.br/produto/codigo-de-processo-civilanotado/. Acesso em 20/05/2020. 
inicial retratar pretensão colidente nos casos destacados. ${ }^{8}$

Neste mesmo sentido, nos casos de necessidade de demonstração da repercussão geral para interposição de Recurso Extraordinário no Supremo Tribunal Federal, um dos óbices a sua admissibilidade é a existência de precedentes do próprio tribunal em relação às questões de repercussão geral, conforme ensina o ministro Alexandre de Morais:

O Presidente do Tribunal recusará recursos que não apresentem preliminar formal e fundamentada de repercussão geral, bem como aqueles cuja matéria carecer de repercussão geral, segundo precedente do Tribunal, salvo se a tese tiver sido revista ou estiver em procedimento de revisão. ${ }^{9}$

Este é um exemplo de vinculação normativa de um precedente, como um modelo de admissibilidade, ao invés de questão de mérito do processo em relação à decisão anterior, mas apenas em relação ao preenchimento de pré-requisitos de análise de recurso.

Os precedentes que não gozam de vinculação obrigatória, não obstante seus efeitos estejam contingenciados aos limites do processo, espelham seus efeitos como modelos, no sentido anteriormente demonstrado, de referência ou modelo para uma situação similar.

Este modelo de precedente traz em sua natureza a própria fundamentação da eficácia, mesmo totalmente desprovido de obrigatoriedade. O artigo 926 do CPC determina critérios relativos à jurisprudência, que deve ser estável, integra e coerente.

Em análise axiológica do mencionado artigo, fica evidente a intenção do legislador no sentido de promover a segurança jurídica e a efetividade, todavia, denota também que este artigo não é destinado apenas aos tribunais, pois as diretrizes que a eles se aplicam, também devem ser dirigidas aos órgãos fracionários e por óbvio, aos juízes singulares.

Desta maneira, nos ditames constitucionais, notadamente ao artigo 93, inciso IX, com também no CPC (artigo 11), a fundamentação é elencada como um dos requisitos das decisões dos órgãos do Poder Judiciário e aplica-se aqui a necessidade de o juiz, obrigatoriamente, afastar o caso em julgamento da alegação de precedentes prevista no CPC.

Dessarte, emerge o efeito de motivação ou de persuasão dos precedentes judiciais não vinculantes, conforme lição de Gilmar Mendes e Paulo Branco:

Isso quer dizer que a fundamentação possui o ônus de colocar a decisão que se prolata na particularidade no campo mais amplo da cadeia das decisões tomadas anteriormente (pode-se dizer, com algum cuidado, precedentes). Registre-se que essa (re)composição da cadeia de decisões precedentes deve respeitar uma coerência interna, não em um sentido simplesmente lógico (aplicação do princípio da não contradição), mas respeitando, também, uma dimensão de equanimidade (fairness) nos termos defendidos por Ronald Dworkin. ${ }^{10}$

8 BUENO, Cassio Scarpinella. Manual de direito processual civil. São Paulo: Saraiva, 2015, p. 267.

9 MORAES, Alexandre de. Direito constitucional. $32^{a}$ edição, rev. e atual. São Paulo: Atlas, 2016, p. 907. 10 MENDES, Gilmar Ferreira. BRANCO, Paulo Gustavo Gonet. Curso de direito constitucional. 12a 
Dentre os ensinamentos obtidos pela leitura da citação acima merece destaque o respeito à coerência, no esteio de decisões tomadas anteriormente, sob a luz de um caso concreto.

$\mathrm{Na}$ busca da coerência, impossível deixar de pensar no que efetivamente convenceu o juiz da aplicação da tese jurídica, ou seja, sua razão de decidir ou ratio decidendi.

Muito importante nesse sentido é a letra da lei no Códex processualista civil, que preceitua em seu artigo 489, parágrafo $1^{\circ}$, inciso $\mathrm{V}$, que a decisão judicial que apenas invocar precedente ou súmula, sem aludir ao caso concreto seus fundamentos e o ajuste fático ao molde delimitado no precedente judicial ou súmula, não é considerada devidamente fundamentada.

Em relação à uniformidade e coerência das decisões judiciais, ensina Lênio Streck que, o liame entre as decisões, em mesma instância ou entre elas, encontram-se muito mais na mente do magistrado do que nas normas positivadas:

Vale dizer, os princípios gerais do direito não possuem força deôntica, mas são acionados apenas em casos de "lacunas" ou de obscuridade da previsão legislativa (esses dois fatores - lacuna e obscuridade - decorrem muito mais da situação hermenêutica do intérprete do que exatamente da legislação propriamente dita). ${ }^{11}$

Desta maneira, na argumentação apresentada pelas partes na causa de pedir, além dos fatos, deve haver a fundamentação jurídica do pedido, atrelando os fatos e os pedidos com base no Direito.

No sistema romano-germânico adotado no Brasil, as leis são positivadas e estabelecem o direito de forma abstrata. A cognição do juiz devera extrair do caso concreto o molde previsto na legislação para conceder ou não os pedidos, essa cognição pode ser influenciada pela forma de interpretação da norma jurídica pelos seus pares, mesmo que essas decisões precedentes não tenham caráter vinculante, mas meramente de motivar sua interpretação de forma similar. Nos dizeres de Daniel Neves:

Precedente é qualquer julgamento que venha a ser utilizado como fundamento de outro julgamento que venha a ser posteriormente proferido. Dessa forma, sempre que um órgão jurisdicional se valer de uma decisão previamente proferida para fundamentar sua decisão, empregando-a como base de tal julgamento, a decisão anteriormente prolatada será considerada um precedente. ${ }^{12}$

O precedente com efeito persuasivo, embora não tenha caráter de efetividade normativa, deve ser observado. Quando o CPC de 2015 institucionalizou o sistema de stare decisis ${ }^{13}$ de forma edição rev. e atual. São Paulo: Saraiva, 2017, p. 864.

11 STRECK, Lenio Luiz. O que é isto - decido conforme minha consciência? - 4. ed. rev. Porto Alegre: Livraria do Advogado Editora, 2013. ISBN 978-85-7348-838-8, p. 98

12 NEVES, Daniel Amorim Assumpção. Manual de direito processual civil - Volume único. $8^{\mathrm{a}}$ edição. Salvador: Ed. JusPodivm, 2016, p. 2328.

13 Stare decisis, para além de ser a repetição da mesma decisão imposta em um caso precedente, significa aplicar a mesma lógica metodológica que foi utilizada em um caso precedente, por se tratar de questão cuja resolução mais justa depende dessa estrutura argumentativa. CAMBI; PITTA, p. 2. 
esparsa, mas inequívoca, em várias de suas partes, apontou claramente para a segurança jurídica e o tratamento isonômico de seus jurisdicionados.

Nesse cariz, as decisões em primeira instancia devem ser tomadas com vistas à jurisprudência dos tribunais superiores, sempre com o intuito de uniformidade das decisões judiciais, para a garantia da coerência. ${ }^{14}$

A valorização pelo CPC de 2015 do sistema de precedentes também é evidente em seu artigo 332, que determina que o juiz julgue liminarmente improcedente o pedido que viole jurisprudência ou os precedentes judiciais vinculantes.

\section{CONCEITOS AFETOS À APLICAÇÃO DE PRECEDENTES}

\subsection{Ratio Decidendi}

Ratio decidendi ou holding é a razão de decidir, são os motivos que fundamentam a decisão. São as razões que obtiveram, de forma determinante, o condão de motivar o magistrado a decidir daquela forma. Na concretização desse conceito, esclarece Barroso:

[...] afirma-se que a ratio decidendi de uma decisão corresponde a uma descrição do entendimento adotado pela corte como a premissa necessária ou adequada para decidir o caso concreto, à luz das razões invocadas pela maioria. Frise-se: a ratio decidendi ou o holding não é o próprio fundamento aprovado pela maioria para decidir. A ratio decidendi ou a tese é uma descrição do entendimento jurídico que serviu de base à decisão. ${ }^{15}$

\subsection{Distinguishing}

Distinguishing em tradução literal, significa distinção. Se a questão objeto da lide é tese jurídica já resolvida e conta com um precedente, este deve ser aplicado ao caso. O raciocínio é eminentemente analógico.

Entretanto, se a tese não for idêntica ou semelhante, ou seja, se não estiverem presentes as características determinantes de similaridade ao precedente, é imperioso que se faça a distinção do caso atual e do precedente, negando-lhe a aplicação, como mostra Barroso:

O que justifica a aplicação de um entendimento anterior a novas causas é o fato de estas serem efetivamente semelhantes àquela em que o precedente se formou. Se forem diferentes, o precedente não incide e o juiz deve indicar o motivo da distinção. ${ }^{16}$

14 BUENO, Cassio Scarpinella. Manual de direito processual civil. São Paulo: Saraiva, 2015, p. 538 a 543.

15 MELLO, Patrícia Perrone Campos; BARROSO, Luís Roberto. TRABALHANDO COM UMA NOVA LÓGICA: A ASCENSÃO DOS PRECEDENTES NO DIREITO BRASILEIRO. Revista da AGU, Brasília-DF, v. 15, n. 03, p. 09-52, jul./set. 2016. p. 27. Disponível em: $<$ http://www.luisrobertobarroso. com.br/wp-content/uploads/2016/11/ Barroso-Campos-Mello-Ascensao-dos-Precedentes.pdf $>$. Acesso em $10 / 04 / 2020$.

16 MELLO, Patrícia Perrone Campos; BARROSO, Luís Roberto. TRABALHANDO COM UMA NOVA LÓGICA: A ASCENSÃO DOS PRECEDENTES NO DIREITO BRASILEIRO. Revista da AGU, Brasília-DF, v. 15, n. 03, p. 09-52, jul./set. 2016. p. 29. Disponível em: <http://www.luisrobertobarroso. com.br/wp-content/uploads/2016/11/ Barroso-Campos-Mello-Ascensao-dos-Precedentes.pdf $>$. Acesso 
Uma vez identificada e estabelecida, portanto, a diferença entre os fatos e/ou aplicação do direito ao caso a ser julgado e àquele julgado por ocasião do precedente que se pretende utilizar, deve ser realizada a distinção entre eles e a tese aplicada a um não deve ser aplicada ao outro da mesma maneira.

\subsection{Obter Dictum}

O termo latim significa no contexto em que se insere, aquilo que é "dito de passagem", sem relevância ao caso concreto em julgamento. Talvez o mais importante desses conceitos analisados, pois é fator delimitador das teses adotadas em precedentes judiciais.

Fundamentado nos princípios do contraditório, do devido processo legal, da inércia da jurisdição e da congruência, o Obter dictum é uma forma de que se permita a criação e o uso de precedentes somente acerca do que foi objeto do caso que é a base da tese jurídica em questão, de modo que esta tenha sido defendida, contradita e concedida, dentro dos requisitos da prestação jurisdicional.

Tem sua importância pois em que pese não seja a ratio decidendi do caso que enseja o precedente, traz argumentações que podem criar novos precedentes ou a superação destes, em casos futuros, pois o direito não é inerte e tão pouco axiologicamente imutável. ${ }^{17}$

\subsection{Overruling}

Outro evento que ocorre na aplicação dos precedentes é o Overruling. Quando uma decisão posterior torna o precedente inconsistente, ocorre sua superação, fenômeno denominado Overruling.

Acontece quando a tese jurídica firmada no precedente se torna impraticável ou o raciocínio que conduz a ela é inadequado. Quando os valores da sociedade determinam razões relevantes para sua superação, o Overrruling é a resposta jurídica à inadequação do precedente pois o mesmo já não corresponde axiologicamente ao sistema social vigente que ensejou a fixação do precedente judicial. $^{18}$

\section{PRINCÍPIOS GERAIS DO DIREITO}

Embora o estudo de princípios deva, em regra, ser feito preliminarmente a analise do objeto em si (neste estudo, o sistema de precedentes adotados pelo CPC de 2015), neste trabalho foi deixado propositadamente por último, pois sua plena compreensão depende da cognição dos requisitos explanados anteriormente.

Em obra clássica contemporânea sobre Direito, de Rubens França, tem-se o conceito de Anaximandro de Mileto sobre princípios, sob a ótica da ciência:

[...] a palavra princípio vem de principium, que significa início, começo, ponto de partida, origem. Em linguagem científica princípio quer dizer fundamento, causa, estrutura. O termo foi introduzido na filosofia por Anaximandro de Mileto,

em $10 / 04 / 2020$

17 p. 09-52, jul./set. 2016. p. 27 a 29. Disponível em: <http://www.luisrobertobarroso.com.br/wp-content/ uploads/2016/11/ Barroso-Campos-Mello-Ascensao-dos-Precedentes.pdf>. Acesso em 10/04/2020.

18 MITIDIERO, Daniel. Precedentes: da persuasão à vinculação. $2^{\mathrm{a}}$ ed. São Paulo: Editora Revista dos Tribunais, 2017, p. 102 e 103. 
filósofo pré-socrático, que viveu entre 610 a 547 A. C. ${ }^{19}$

Sua compreensão é de máxima importância pois além de possibilitar o entendimento do porquê se introduziu em um ordenamento secular - onde a base é a lei - um sistema vinculante baseado em costumes (embora o conceito de costumes para o Common Law seja distinto), ainda permite ao operador do direito, notadamente ao litigante mais preparado, fundamentar sua causa de pedir em princípios sólidos, que deram razão de ser aos alicerces legais positivados, em franca vantagem processual na seara processualista cível hodierna.

Destarte, infere-se que os princípios fundantes dos alicerces processuais brasileiros continuam a ter a característica eminentemente legalista, ou seja, tem a base na lei, sendo os precedentes judiciais (aqui cita-se o costume, com certa reserva, como já mencionado alhures) uma maneira de uniformizar as interpretações legais, nas palavras de Maria Helena Diniz:

O costume é, portanto, uma norma que deriva da longa prática uniforme ou da geral e constante repetição de dado comportamento sob a convicção de que corresponde a uma necessidade jurídica. A fonte jurídica formal é, então, a prática consuetudinária, sendo o costume ou a norma costumeira uma forma de expressão jurídica; deveras o costume não gera o direito, é apenas um modo pelo qual ele se expressa. ${ }^{20}$

A maneira como os juízes interpretam as normas positivadas deve seguir então o sentido majoritário do poder judiciário, não possuindo este a prerrogativa de criar novas normas, apenas tem a finalidade de trazer coesão ao sistema judicial.

Esta característica obedece à isonomia dos poderes. Coaduna este entendimento a opinião acerca do destino do sistema jurídico brasileiro Flávio Tartuce, se não, veja-se:

A conclusão, portanto, é pela permanência, pelo menos por enquanto, de um sistema essencialmente legal. Como é notório, o princípio da legalidade está expresso no art. $5^{\circ}$, inc. II , da Constituição Federal de 1988 , pelo qual ninguém será obrigado a fazer ou a deixar de fazer algo senão em virtude da lei. ${ }^{21}$

Outrossim, destaca-se o viés ético na conduta dos envolvidos na lide processual, tanto em relação à causa de pedir como na motivação das decisões. Malgrado a questão de ética seja de conceituação ampla e de várias vertentes, analisar-se-á nesta pesquisa a ética como um dever de agir conforme princípios morais.

Não é ético o juiz negar a motivação citada como precedente, se no molde proposto

19 FRANÇA, Rubens Limongi. Enciclopédia Saraiva de Direito. Volume 60. São Paulo: Saraiva, 1977, p. 505.

20 DINIZ, Maria Helena. Enciclopédia Jurídica da PUCSP, Tomo I: Teoria geral e filosofia do direito. São Paulo: Pontifícia Universidade Católica de São Paulo, 2017. p.11. Disponível em: <https:// enciclopediajuridica.pucsp.br/pdfs/fontes-do-direito 5994a67e78911.pdf> Acesso em 30/05/2020.

21 TARTUCE, Flávio. Manual de direito civil: Volume único. $6^{a}$. Edição. São Paulo: Editora Método, 2016, p. 32. 
provam-se a presença de todos os requisitos para tal finalidade, como se, ao fazê-lo, negasse a própria cognição das razões, escusando a verdadeira análise do caso, como se pode entender pela lição acerca da busca da verdade por Aristóteles:

O princípio da ação é a decisão (isto é, enquanto origem da motivação, não enquanto fim em vista); por outro lado, o princípio da decisão é a intenção e um cálculo dirigido para um objetivo final. Por esta razão, não há decisão sem o poder da compreensão, nem sem processo compreensivo, nem, finalmente, sem a disposição do caráter. Na verdade, agir bem e o seu contrário não existem na ação sem o pensamento teórico nem sem a disposição ética. ${ }^{22}$

Desta maneira, quando os litigantes estabelecem sua causa de pedir, fundamentam seus pedidos na certeza do direito, base da segurança jurídica. $\mathrm{O}$ juiz por sua vez, deve agir de modo coerente com o sistema judiciário, do qual integra.

\section{CONCLUSÃO}

Os sistemas de direito Civil Law e Common Law têm na origem de suas fontes sua principal distinção, não obstante, sob uma análise epistemológica, seus valores se entrelaçam e até mesmo se confundem. Em que pese à miscigenação dos valores referentes aos sistemas jurídicos, não seria correto interpretar, a partir disso, que existe uma invasão de modelos e princípios do common law no direito brasileiro

Ademais, apesar das normas jurídicas emergirem de fontes diversas, têm no objetivo seu ponto de convergência, onde a prestação jurisdicional concretiza os valores intrínsecos no ordenamento de cada sistema, mesmo que por caminhos diversos, mas de forma coerente.

O CPC de 2015 não transfigura suas origens, apenas abarca como fonte material do direito o sistema de precedentes, que desde a vigência da Constituição Federal de 1988 promove uma busca pela efetividade da prestação jurisdicional e pela sua coesão.

A inserção dessa fonte do direito, ou por melhor dizer, desse paradigma processual, além de vir assentado na fonte primária do Civil Law, haja vista que o precedente deve, obrigatoriamente, ter sido julgado com base na lei, alça as decisões tomadas a posteriori ao nível de jurisprudência, pois se equipara a ela devido a solidez de sua fundamentação.

A trajetória dos precedentes dentro do ordenamento jurídico pátrio é lenta e progressiva, e talvez essa seja sua principal crítica, principalmente pelos estudantes do direito comparado, tendo em vista que sua força vinculante não encontra similaridade com o sistema Common Law, de forma que sua incidência, excetuado os casos previstos no CPC, pode limitar-se a persuasão ou motivação.

Entretanto, as adequadas operações desse sistema híbrido - como gostam de chamá-lo seus críticos - aliada à obrigatoriedade da fundamentação das decisões judiciais, indubitavelmente é

22 ARISTÓTELES. Ética a Nicômaco. Tradução do grego de António de Castro Caeiro. São Paulo: Editora Atlas, 2009. p. 130. 
uma ferramenta valiosíssima do operador do direito, pois além de permitir a argumentação acerca do tema, estabelece um paradigma que deve ser respeitado e que, se for recusado, deve sê-lo através de fundamentação sólida.

É de máxima importância, contudo, que as noções primárias desse sistema, que tem sua origem no Common Law e dele por essa razão não possam ser definitivamente afastadas, sejam estudadas e bem compreendidas, pois a razão de ser do modelo é mais importante que o precedente em si mesmo, de modo que para a utilização eficaz do instituto, se deve dominá-lo, no sentido de compreender como e porque a tese foi estabelecida e principalmente, quais eram os reais valores com que, naquele caso concreto antecedente, pretendeu-se fundar a decisão.

A observância dos precedentes deve ser levada a sério, tanto pelos juízes na tomada de suas decisões como pelos litigantes na hora de postular, pois em que pese no Brasil praticamente não haja histórico de respeito aos precedentes, o novo códex processual tratou de atribuir-lhes eficácia normativa.

Dentre os valores que justificam a adoção do sistema de precedentes no Brasil, três indubitavelmente merecem destaque: A segurança jurídica, a isonomia e a eficiência.

Esses valores se correlacionam, se completam e até se limitam na busca pela prestação jurisdicional justa, plena e efetiva, com objetivo de por fim a loteria jurídica existente sem tais balizas principiológicas.

Impensável um sistema jurídico coerente capaz de emanar decisões diametralmente opostas baseadas nas mesmas situações fáticas e na mesma legislação.

O conceito de tese jurídica valorizado pelo CPC de 2015 estabiliza, de certa forma, a Ratio decidendi da aplicação de precedentes judiciais. Como exemplo de teses que visam motivar as decisões que não estão vinculadas por efeito normativo, pode-se elencar de forma mais significativa a "Jurisprudência em Teses" do STJ ${ }^{23}$, que apesar de não se tratar propriamente de precedentes vinculantes, tem forte apelo motivacional, de forma similar aos precedentes não vinculantes.

Passados mais de trinta anos da promulgação da Constituição Federal de 1988, retorna-se a ideia de Norberto Bobbio ${ }^{24}$, qual seja, que após se ultrapassar o tempo de saber quais e quantos são os direitos, sua natureza ou fundamento, o problema agora é encontrar maneiras de torná-los efetivos.

Nesse compasso, os precedentes judiciais se apresentam como uma das muitas formas de atribuir coerência ao sistema, bem como segurança no julgamento e consequente pacificação social, que é o intuito principal do Direito.

Tudo isso deve ocorrer sem se olvidar da cautela necessária ao se colocar lado a lado sistemas diversos, com raízes variadas e forma de evolução ainda mais diversificada.

Feita tal análise, há que se manter foco no desenvolvimento do sistema dentro do ordenamento a que se destina. Nesse quesito, muitas são as medidas obrigatórias, entre elas, a difusão da técnica e a máxima padronização da conduta dos julgadores na aplicação da metodologia,

23 STJ, Jurisprudência em Teses. Disponível em: <http://www.stj.jus.br/SCON/jt/.> Acesso em $28 / 05 / 2020$.

24 BOBBIO, Norberto. A era dos direitos. Rio de Janeiro: Editora Campus, 1992, p. 25 
que exige grande esforço argumentativo e análise profunda dos casos comparados.

\section{REFERÊNCIAS}

ARISTÓTELES. Ética a Nicômaco. Tradução do grego de António de Castro Caeiro. São Paulo: Editora Atlas, 2009.

BOBBIO, Norberto. A era dos direitos. Rio de Janeiro: Editora Campus, 1992.

BRASIL. Código de processo civil (Lei ordinária 13105/2015). Diário Oficial [da] República Federativa do Brasil, Poder Executivo, Brasília, D.O.U. DE 17/03/2015, P. 1. Disponível em: $<$ http://www.planalto.gov.br/ccivil_03/_ato2015-2018/2015/lei/113105.htm>. Acesso em 20/05/2020.

BRASIL. Constituição da República Federativa do Brasil de 1988. Diário Oficial [da] República Federativa do Brasil, Poder Executivo, Brasília, DF, 05 out. 1988. 191-A p. 1. Disponível em: < http://www.planalto.gov.br/ccivil_03/constituicao/constituicao.htm.>. Acesso em 21/05/2020.

BUENO, Cassio Scarpinella. Manual de direito processual civil. São Paulo: Saraiva, 2015.

CÂMARA, Alexandre Freitas. O novo processo civil brasileiro. São Paulo: Atlas, 2015.

CAMBI, Eduardo. PITTA, Rafael Gomieiro. SISTEMA DE PRECEDENTES BRASILEIRO: COMPREENSÃO CRÍTICA A PARTIR DA TRADIÇÃO INGLESA E NORTEAMERICANA.

CONCEIÇÃO, Maria Lucia Lins. Código de processo Civil Anotado. AASP, OAB Paraná, ISBN 978-85-86893-00-1, 2017, Disponível em: https:/www.aasp.org.br/produto/codigo-deprocesso-civil-anotado/. Acesso em 20/05/2020.

DINIZ, Maria Helena. Enciclopédia Jurídica da PUCSP, Tomo I: Teoria geral e filosofia do direito. São Paulo: Pontifícia Universidade Católica de São Paulo, 2017.

Disponível em: <https://enciclopediajuridica.pucsp.br/pdfs/fontes-do-direito_5994a67e78911. pdf $>$ Acesso em 30/05/2020.

FRANÇA, Rubens Limongi. Enciclopédia Saraiva de Direito. Volume 60. São Paulo: Saraiva, 1977.

MARINONI, Luiz Guilherme. Precedentes obrigatórios. São Paulo: Editora Revista dos Tribunais, 2010.

MELLO, Patrícia Perrone Campos; BARROSO, Luís Roberto. TRABALHANDO COM UMA NOVA LÓGICA: A ASCENSÃO DOS PRECEDENTES NO DIREITO BRASILEIRO.

Revista da AGU, Brasília-DF, v. 15, n. 03, p. 09-52, jul./set. 2016. Disponível em: <http://www. luisrobertobarroso.com.br/wp-content/uploads/2016/11/ Barroso-Campos-Mello-Ascensao-dos- 
Precedentes.pdf>. Acesso em 10/04/2020.

MENDES, Gilmar Ferreira. BRANCO, Paulo Gustavo Gonet. Curso de direito constitucional. $12^{\mathrm{a}}$ edição rev. e atual. São Paulo: Saraiva, 2017.

MITIDIERO, Daniel. Precedentes: da persuasão à vinculação. $2^{\mathrm{a}}$ ed. São Paulo: Editora Revista dos Tribunais, 2017.

MORAES, Alexandre de. Direito constitucional. 32ª edição, rev. e atual. São Paulo: Atlas, 2016.

NEVES, Daniel Amorim Assumpção. Manual de direito processual civil - Volume único. $8^{\mathrm{a}}$ edição. Salvador: Ed. JusPodivm, 2016.

REALE, Miguel. Filosofia do direito. 19ª edição, 3ª tiragem. São Paulo: Saraiva, 2002.

STJ. Jurisprudência em Teses. Disponível em: $<$ http://www.stj.jus.br/SCON/jt/.> Acesso em 28/05/2020.

STRECK, Lenio Luiz. O que é isto - decido conforme minha consciência? - 4. ed. rev. Porto Alegre: Livraria do Advogado Editora, 2013. ISBN 978-85-7348-838-8

TARTUCE, Flávio. Manual de direito civil: Volume único. $6^{\text {a }}$. Edição. São Paulo: Editora Método, 2016.

Recebido em:11/05/2020

Aprovado em :01/06/2020 